\title{
COMPLEX AUTOMATED INFORMATION SYSTEM FOR REMOTE MANAGEMENT OF CRISIS SITUATIONS IN RAIL TRANSPORT
}

The paper deals with topical information from the area of crisis information support. The contributing authors work at three co-operating universities where the subject of transport support in crises is tackled. At present the electronic support of crisis management in transport is necessary prerequisite for the functioning of transport system under both common and emergency situations. The outcomes of scientific research projects are new even from a broader European perspective. The preparation of complex automated information system for remote management of crisis situations in rail transport is new and has not been published yet. The outcomes of extensive analysis, gradually developed methodologies and data sets are presented in the paper together with the current outcomes regarding the electronic support of crisis management in transport.

Keywords: Crisis situation, transport security, information support, information system, rail transport.

\section{Introduction}

During the last decade the global security research was markedly focused on solving the problems of critical infrastructure. The USA in co-operation with Canada has developed their own electronic expert information system [1] the aim of which is to reduce risks in all sectors of critical infrastructure. A significant progress in the area of electronic information support has been made mainly in Australia [2] and [3].

The European security research in the area of critical infrastructure is carried out in two lines. Firstly it is the EU's Seventh Framework Programme and its "Security" calls. Several extensive projects focused on the protection of critical infrastructure are solved every year within this call. The significant projects in this area are Comicin, Micie, and WSAN4CIP [4] and [5].

The European Union and its member states have started preparing their own European Critical Infrastructure Warning Information Network (CIWIN). Building other information portals is an important part contributing to the protection of critical infrastructure. One of them has been prepared within the European educational project called Competency Based e Portal of Security and Safety Engineering. Work on the project was in progress from 20092012 at Zilina University and the "eSEC" portal was the outcome of it [6]. The authors participated in the preparation of the following projects within the national projects on the protection of critical infrastructure:
- Project APVV-0202-12 on Communication Technologies Aided Protection of Critical Infrastructure in the Slovak Republic (the project is in the assessment phase)

- Complex Automated Information System for Remote Management of Crisis Situations in Rail Transport with Focus on Critical Infrastructure is the project prepared in the Czech Republic. The work on the project is planned for years 2012-2015.

Real crisis and emergency events, which often occur in transport and energetic infrastructure, threaten population and surrounding facilities. At present there are not any complex information systems enabling the transfer of information from the administrator of infrastructure to regional structures and vice versa [4] and [5]. The aim of the paper is to present the project of applied research, which would contribute through communication technologies to the improved exchange of information during crises and emergencies.

The project VG20122015070/Ministry of Interior of the Czech Republic on the "Complex Automated Information System for Remote Management of Crisis Situations in Rail Transport with Focus on Critical Infrastructure", called KISDIS, started in 2012. The first stage included the information analysis of available materials abroad with the aim to find similar projects carried out in particular European countries. The outcomes of the analysis confirmed that the electronic support for the management of crisis situations in rail transport has not been solved in any of the countries included in the survey.

\footnotetext{
* Zdenek Dvorak ${ }^{1}$, Maria Luskova ${ }^{1}$, Petr Hruza $^{2}$, Radovan Sousek ${ }^{3}$

${ }^{1}$ Research Department of Crisis Management, University of Zilina, Slovakia, E-mail: zdenek.dvorak@fsi.uniza.sk

${ }^{2}$ University of Defense, Brno, Czech Republic

${ }^{3}$ Radovan Sousek, Department of Transport Technology and Control, University of Pardubice, Pardubice, Czech Republic
} 
Lessons learned from extensive floods in the Czech and Slovak Republic in the last decade clearly showed the need for rapid and efficient dissemination of information to experts, as well as public. Therefore experts on rail transport co-operate with experts on regional crisis management during their work on the project.

There have been 23 types of hazards defined and accepted by all departments in the Czech Republic [7] and [8]. The first stages of the project in 2012-2013 are aimed at developing the methodology which will exploit earlier defined types of hazards in the area of rail transport of the Czech Republic. With regard to the overall goal of the project it was necessary to define a functioning data set, which will be the basis for the future expert information system. The outcomes of initial stages are very original. The proposed methodology has been tested in the conditions of rail transport and it is assumed that it will be certified on a national level. The outcomes of initial stages have become a real basis for the functioning of future complex information system for remote management of crisis situations in rail transport.

\section{Outcomes of the analytical part of the project}

The whole analysis of the project has been aimed at updating a large information base. Updated information has been collected on the ways critical infrastructure is protected in the transport sector in Germany, Poland, Austria and the Slovak Republic. Special attention has been paid to the current outcomes of the projects within the $7^{\text {th }}$ EU Framework Programme aimed at improving the long-distance control of rail transport and the information support of crisis management. A significant part of analytical survey has been focused on a comparative analysis of legal environment in particular European countries. Bearing in mind the main aim of the project the further effort has been made to analyse mutual compatibility of the systems transferring the information from the information system through internet to SMART mobiles. The testing of individual mobile phones operational systems and the assessment of possible risks resulting from the transfer of information between an internet server and SMART mobiles were other significant analytical activities. At present the crisis management staff on rail has been gradually equipped with intelligent mobiles. Further procedure has been set within the KISDIS project based on the above mentioned analysis.

The methodology for the selection of hazards has been preconditioned by a number of constraints. The first condition was the fact that rail transport is considered to be a compact system. For the needs of the research the rail transport infrastructure has been divided into individual railway lines and stations. The method of generalization has been applied for acquiring corresponding parameters and the railway lines (or their parts) have been classified into several types. The second condition was to divide railway stations into five classification categories. Such an approach required the documentation for one station and one type of railway line. Different types were distinguished by names in operational documentation then.
The procedure of activities according to the methodology represents the first step in the process of planning the measures for managing the crisis situations on rail and requires a good knowledge of the assessed railway line, terminology of transport, logistic and construction guidelines of the Railway Infrastructure Administration (hereinafter RIA). The methodical instructions enable not only the selection of hazards from the list provided by the railway controller crisis information system. The methodology is logically ordered in compliance with the definition of hazard as one source of risk. Prior the final determination of particular type of hazard it integrates the completed analyses into one table in the order which is introduced in the KISDIS programme software environment

\subsection{Multicriterial assessment of possible impacts}

Impacts on rail infrastructure (a subsector of critical infrastructure) are assessed by comparing a selected location with assumed consequences. The assessment includes both a particular location of critical infrastructure and the possibilities that a particular event may have an impact on the functionality of the element of critical infrastructure [9] and [10].

In case the location is hazardous, or the consequences have impact on the functionality of the element of critical infrastructure, its identification is changed (e.g. highlighted) and considered to be of higher priority during further processing. The multicriterial assessment is carried out in the following order of importance:

1 The determination of hazardous location;

2 The determination of risk source;

3 The activation of risk source;

4 Reason why the risk source may be activated;

5 Event which may occur upon the activation of risk source;

6 Assumed consequences [11].

Risk sources are always connected with a particular location. The crossings of railway lines with other line infrastructures are very frequent activation mechanisms of risks. Other frequent causes include unintentional mistakes of traffic participants, extreme weather conditions and technical breakdowns. The research team ambition is to develop a fully automated complex system for remote management of emergencies [12] and [13].

\subsection{General classification of hazards on railway}

The authors firstly defined the general classification of hazards for rail transport on the basis of extensive analyses of real emergencies in rail transport and with the effort to employ the existing classification of hazards. The risk sources were transferred into particular hazard type names due to the preparation of a model and possible programming. It is registered in one sentence consisting of four parts, i.e. EVENT - RISK SOURCE ACTIVATION - LOCATION - CAUSE, in the following format:

1. "name of EVENT" caused by;

2. "name of RISK SOURCE ACTIVATION"; 
3. in "name of LOCATION";

4. caused by "name of CAUSE".

Note: information written in quotation marks is inserted automatically from the database.

The range of own analytical research activities is evident from the decreasing number of generated types of hazards. All possible types of hazards, i.e. 12,032, were generated in the initial proposal. By removing the duplications their number decreased to 2,800. Extensive expert discussions and the removal of unlikely hazards with negligible impacts resulted in 627 types of hazards, which are significant part of the proposed methodology.

The term change of operational conditions is used in the methodology for naming all the EVENTS on the railway. It may be characterized as a course of action which disturbed the traffic on railway and in order to identify the type of event better it may be subdivided in the following way:

- the stoppage of traffic - hazard may result in inability to operate the rail transport;

- the change of schedule - hazard may result in the reduced range of transport;

- the change of technology - hazard may have an impact on the work scheme;

- the change of service - although the infrastructure is not disturbed, the identified hazards may result in the change of services being offered.

The second important step is naming the RISK SOURCE ACTIVATION, which stems from the identification of risk sources. The risk sources identified in rail transport are facilities in railway infrastructure, railway buildings, constructions, operational personnel, customers and buildings and facilities near the railway line. Expert analyses, which took several months, defined 35 activation mechanisms altogether (e.g. fire, flood, explosion, collision, etc.).

The third step includes analysing the location of the type of hazard by connecting the activation mechanisms with the risk sources. There were 50 possible combinations defined during an extensive expert discussion. These combinations in railway transport are significant and of quite high probability.

The CAUSES were divided into two basic groups (natural and man-made). The further procedure was based on putting them in relation to risk source activation. The risk source activation was related to location in the previous step (e.g. railway line, station, building, train). Probability of such combinations has to be always assessed. Unreal combinations have been excluded from further analysis. More causes have been considered (i.e. synergic effect) when calculating the type of threat. Their assessment and ordering resulted in 14 groups of causes according to their common characteristics, part of which is shown in Table 1. They are written into the type of threat under the term in the column "name of Cause".

General description of the types of hazards in rail transport has been developed according to the above mentioned procedure
Table of particular causes in relation

Table 1

to the name of cause (sample)

\begin{tabular}{|c|l|l|}
\hline No & Name of cause & Content \\
\hline 1 & $\begin{array}{l}\text { Atmospheric } \\
\text { and cosmic } \\
\text { anomalies }\end{array}$ & $\begin{array}{l}\text { Storm, other electric phenomena in the } \\
\text { atmosphere, cosmic radiation, magnetic } \\
\text { anomalies, meteor impact }\end{array}$ \\
\hline 2 & $\begin{array}{l}\text { Biological } \\
\text { emergency }\end{array}$ & $\begin{array}{l}\text { Extremely increased reproduction of insects } \\
\text { transmitting the infection, increased numbers of } \\
\text { weeds, viruses, bacteria, animal vermin, wild } \\
\text { infected animals }\end{array}$ \\
\hline
\end{tabular}

and in numerous, documented expert discussions. Note: Similar general description of the types of hazards has been simultaneously developed for road transport, but this is not further pursued within this project. Thus the methodical basis has been developed for the future expert information system for remote management of emergencies in rail transport. It is obvious that its real functioning requires available and realistic data set.

\section{Outcomes discussion}

The standard part of applied research is the analysis of acquired outcomes and discussion about their benefits for the project. The acquired theoretical and practical outcomes may be assessed in the following levels. The first set of outcomes was based on a partial goal, which was aimed at identification and selection of suitable data. This goal has been met by creating the real data sets within the KISDIS project. The second set of outcomes has been aimed at real and practical benefits of the methodology for selecting and processing the types of hazards. The third set of outcomes resulted in the domain analysis and model cases to be employed in practice.

\subsection{Identification and selection of suitable data}

The most significant data basis for the types of hazards in transport is The Type Plan of the Ministry of Transport called "LargeScale Disturbance of Transport System Functionality" [7]. At present the Plan has five annexes dealing with individual types of transport. The annexes are focused on rail transport, road transport, road economy, civil aviation, and domestic water transport.

The Type Plan provides users with data for crisis planning in rail transport. It also lists the risks related to the railway traffic, scenarios of development of crisis situations, primary and secondary impacts of crisis situations, conditions and prerequisites for managing the crisis situations, recommended type procedures, and requirements for resources.

Crisis plan is another significant data basis. It includes the summary of planning, methodical and information documents and data required for decision-making, control and co-ordination activities in a crisis situation. It standardizes the procedures of crisis 
management authorities in the area of transport, provides basic data and characteristics of possible crisis situations (it includes type plans) and determines possible solutions including their impacts on transport.

\subsection{Methodology for selecting and processing the types of hazards}

The development of the methodology for selecting and processing the types of hazards was the main aim of the initial phase of the KISDIS project. Determining the types of hazards was the synthesis of general criteria, which includes all possible combinations generated from the event, risk source activation, location and cause. The names have been compiled into a sentence in the following form and order (see Table 2):

Syntax of creating the name for the type

Table 2 of hazard in the KISDIS project

\begin{tabular}{|l|l|l|l|}
\hline Event & $\begin{array}{l}\text { Risk source } \\
\text { activation }\end{array}$ & Location & Cause \\
\hline $\begin{array}{l}\text { Change of } \\
\text { operational condi- } \\
\text { tions due to }\end{array}$ & $\begin{array}{l}\text { Bombardment of } \\
\text { railway vehicle }\end{array}$ & $\begin{array}{l}\text { On the } \\
\text { railway line }\end{array}$ & $\begin{array}{l}\text { Atmospheric and } \\
\text { cosmic anomalies }\end{array}$ \\
\hline $\begin{array}{l}\text { Change of } \\
\text { operational condi- } \\
\text { tions due to }\end{array}$ & $\begin{array}{l}\text { Immobility of } \\
\text { traction vehicle }\end{array}$ & In train & $\begin{array}{l}\text { Mistake caused } \\
\text { by human factor. }\end{array}$ \\
\hline
\end{tabular}

Defining the types of hazards, their testing and verification in co-operation with experts on rail transport and regional crisis management resulted in the summary Table containing 627 types of relevant and quite probable types of hazards. The type names of hazards have become the basic database for prepared expert information system.

\subsection{The model of system employment}

The KISDIS information system consists of control and monitoring nodes. It includes at least one control node with the KISDIS Windows system and at least one monitoring node with the KISDIS Internet system. In case of need a monitoring node of another information system may be added to the KISDIS system.

The main part of the KISDIS Windows system consists of three main components (see Fig. 1):

- KISDIS Windows Client,

- KISDIS Windows Mobile,

- KISDIS Windows Server.

The KISDIS Windows Client component will serve for inserting and editing the information on the management of crisis situations in the database. The KISDIS Windows Client component will be installed into the crisis manager's work station.
The KISDIS Windows Mobile component will serve for receiving, displaying and reverse sending of information on the duties of task forces. This component will be installed into the task forces' mobile phones.

The KISDIS Windows Server component will provide the exchange of information between the KISDIS Windows Client and the KISDIS Windows Mobile components. The information will be stored into the KISDIS database. Each control node will have one KISDIS database.

The mutual independence of all three components has been chosen as the main criterion of functionality of the whole KISDIS Windows system. Thus each component has been operational even in case the other components are not. The following Figure shows the basic employment of individual components of the KISDIS Windows information system and their inter relations.

The surrounding co-operating information systems are standard e-mail servers enabling communication through IMAP and SMTP protocols and database servers or database files. Smart phones and Internet infrastructure are also parts of surrounding co-operating systems.

The KISDIS Internet system consists of the network of servers - nodes of the "KISDIS Internet Server" type and remote users nodes of the "Remote user" type (see Fig. 2). The servers use HTTP server for providing information in the form of web pages. The servers may mutually update their data through the port types of web services. Server also implements the port types for the third parties' information systems - node "Another remote server".

The remote users cannot communicate directly with each other within the KISDIS network; they are in the role of a client.

\section{Conclusion}

The first outcomes of the KISDIS project have been published in the paper. The universal employment of the proposed expert information system in relation to the administrator of critical infrastructure and public administration is a prerequisite for its future employment in the Czech Republic and possibly in other EU countries. The authors of the project believe that other activities of the project will result in the certification of the developer methodology on a national level. The primary goal of the project is to improve the information support of crisis management in two different areas - in rail transport and municipal crisis management.

The first stage of the project is dealing with risk sources identification, development of basic data structure for the future expert information system and structure of the proposed measures. Within the risk sources identification the first stage was oriented on creating a list of all theoretically possible threats in a railway transport. Their total number was 12032 but after elimination of the contentual duplicities their number changed to 2800 threats that will be used in the expert system. Working with data structure was 


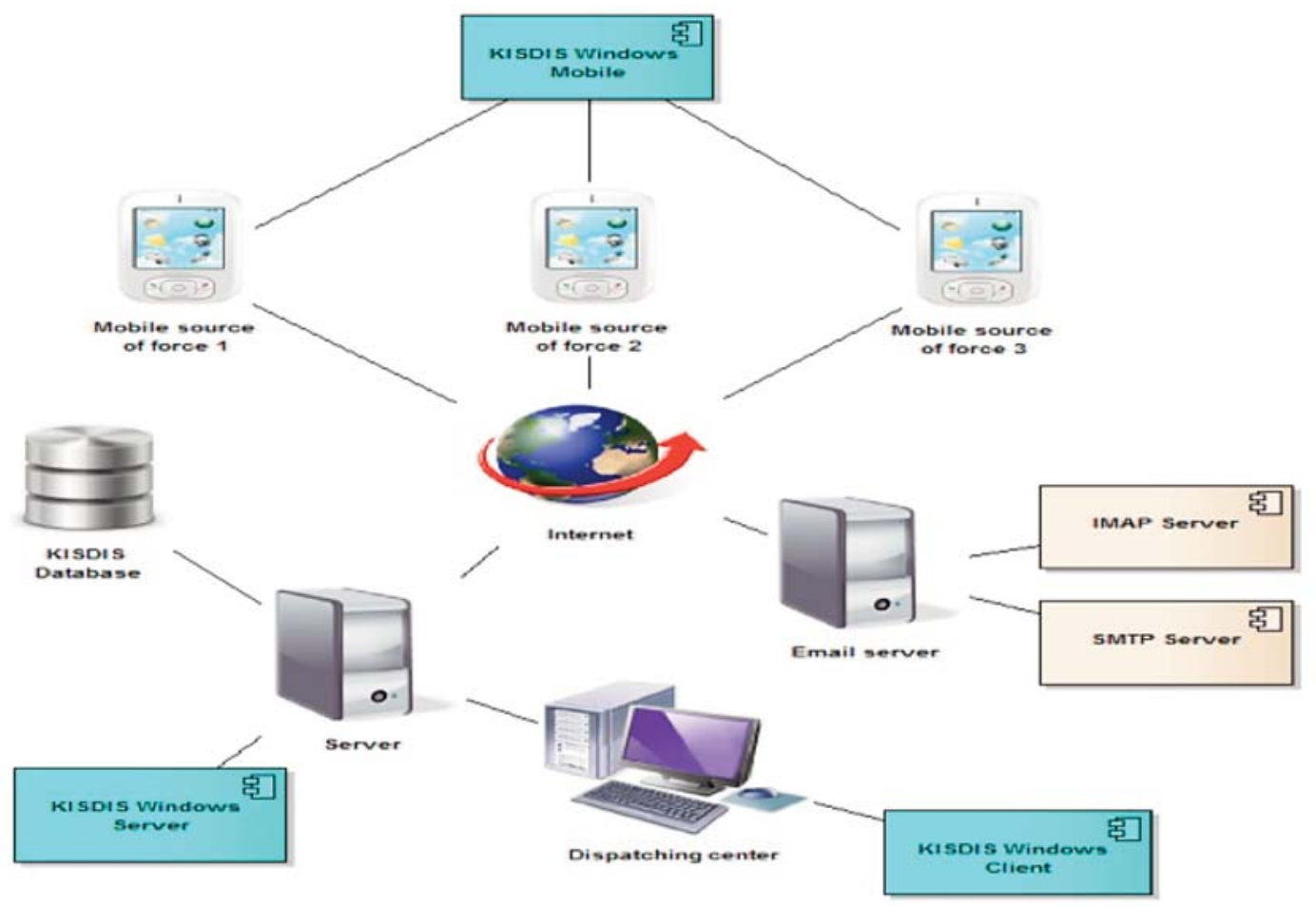

Fig 1. Basic KISDIS Windows model of employment

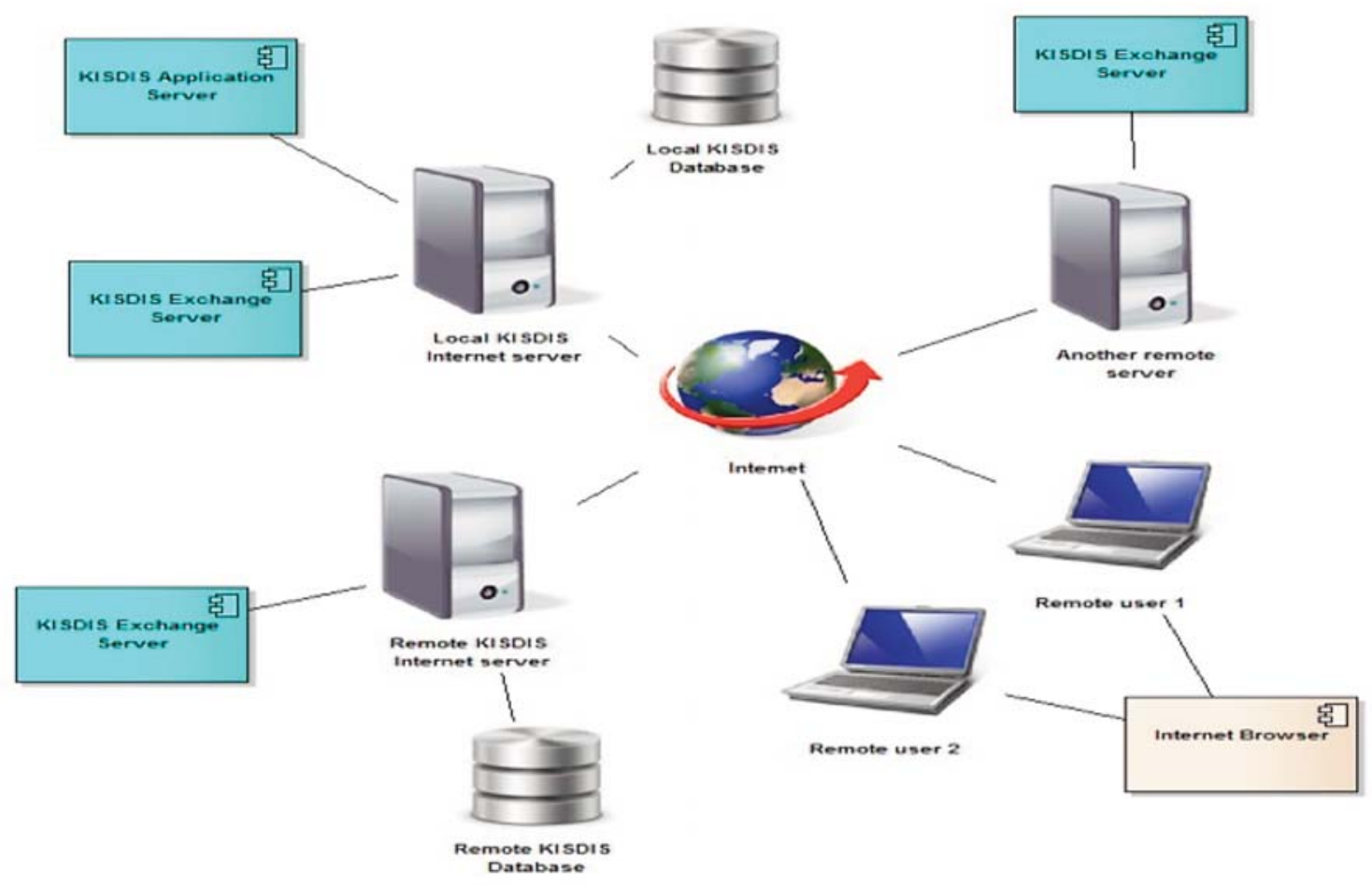

Fig. 2 KISDIS Internet - basic model of employment 
oriented on exact description of the event, risk activating mechanism, place and causes. In successive steps 615 type of threats were specified that will be detailed and elaborated in the form of standard recommendations file.

\section{Acknowledgements:}

The outcomes presented in this contribution are part of the project on "The Complex Automated Information System for
Remote Management of Crisis Situations in Rail Transport with Focus on Critical Infrastructure". The project is granted by the Ministry of Interior of the Czech Republic under No. VG20122015070. The authors would also like to thank the "Centre of Excellence for Systems and Services of Intelligent Transport" (ITMS 26220120028) for building the infrastructure being used.

\section{References}

[1] DVORAK, Z., FUCHS, P., NOVAK, J., SOUSEK, R.: Individual and Social Risk During Transportation of Dangerous Substances, Communications - Scientific letters of the University of Zilina, ISSN 1335-4205, vol. 13, No. 2, 2011,

[2] Web:http://www.tisn.gov.au/Documents/Australian+Government+s+Critical+Infrastructure+ Resilience+Strategy.pdf

[3] RISTVEJ, J., ZAGORECKI, A.: Information System for Crisis Management - Current Applications and Future Directions, Communications - Scientific Letters of the University of Zilina, ISSN 1335-4205. vol. 13, No. 2/2011

[4] Web: http://cordis.europa.eu/fp7/ict/critinfpro/projects_en.html

[5] Web: http://www.future-internet.eu/activities/fp7-projects.html).

[6] Web: http://.eSECportal.eu

[7] Type Plan of the Ministry of Transport. Large-Scale Disturbance of Transport System Functionality. Ministry of Transport of the Czech Republic No. 116/2010-030-CRS, $1^{\text {st }}$ November 2010

[8] Crisis Plan of the Ministry of Transport of the Czech Republic, No. 32/2005-CNP by $15^{\text {th }}$ March 2005. Prague, Ministry of Transport, 2005

[9] VIDRIKOVA, D., DVORAK, Z., KAPLAN, V.: The Current State of Protection of Critical Infrastructure Elements of Road Transport in Conditions of the Slovak Republic, Proc. of $15^{\text {th }}$ intern. conference Transport Means 2011, Kaunas University of Technology, 2011

[10] DVORAK, Z., SOUSEK, R. ENGLICH, J.: Preparation for Solution of Crisis Situations in Railway Transport in the Czech Republic. Logistyka i Transport, Poland, 2007

[11] SOUSEK, R. et al: Methodology of Critical Transport Infrastructure Objects Identification. Proc. of $5^{\text {th }}$ intern. scientific conference Theoretical and practical issues in transport, Pardubice, University of Pardubice, 2010

[12] DVORAK, Z., LEITNER, B., SVENTEKOVA, E., SOUSEK, R.: Managing of Risks in Railway Transport, Monograph Institute J. Pernera, University of Pardubice, 2011

[13] MAJERNIK, M., PANKOVA JURIKOVA, J.: Theoretical Methodological Aspects of Integrated Risk Management Standardization, Communications - Scientific Letters of the University of Zilina, vol. 13, No. 2, 2011, ISSN 1335-4205. 